\title{
Effects of 7YSZ doping on properties of lanthanum cerate coatings
}

\author{
Qing $\mathrm{He}^{1},{ }^{\mathrm{a}}$, Hongfeng Yan ${ }^{1},{ }^{\mathrm{b}}$, Yufen $\mathrm{Lv}^{1},{ }^{\mathrm{c}}, \mathrm{Han}_{\mathrm{Zou}}{ }^{1}, \mathrm{~d}$, \\ Ruijun Wang ${ }^{1},{ }^{e}$, Weiping Wang ${ }^{1}{ }^{f}$ \\ ${ }^{1}$ Chinese Academy of Agricultural Mechanization Sciences, Beijing, 100083, China \\ a heqing68@gmail.com, bhongfeng216@163.com, ㄷa_yf@sina.com, \\ dzouhan_happy@126.com, ${ }^{\mathrm{e}}$ wangruijun@sina.com, ${ }^{\mathrm{f}}$ tezhongsuo@sina.com
}

Keywords: Lanthanum cerate, 7YSZ doped; Thermal physical properties; Sintering-resistance Abstract. Lanthanum cerate $\left(\mathrm{La}_{2} \mathrm{Ce}_{2} \mathrm{O}_{7}, \mathrm{LC}\right)$ is a typically material with fluorite structure, which an attractive new generation TBC material due to low thermal conductivity, relative higher thermal expansion coefficient and excellent high temperature phase stability. Sintering-resistance of LC sharply decreased above $1518 \mathrm{~K}$ is the main reason for LC as new TBC with target service temperature above $1573 \mathrm{~K}$. The effect of 7YSZ doping LC on thermal physical properties, sintering-resistance were studied. $\mathrm{La}_{2} \mathrm{Ce}_{2.5} \mathrm{O}_{8}$ sprayed powders doped with 1 10mass\% 7YSZ were synthesized by solid-phase synthesis and agglomerated-sintering method, and ceramic coatings were prepared in the same process condition. The LC coatings doped with $7 \mathrm{YSZ}$ retained lower thermal conductivity $\left(0.7 \sim 0.8 \mathrm{~W} \cdot \mathrm{m}^{-1} \mathrm{~K}^{-1}\right.$ at $1573 \mathrm{~K}$ with about $80 \%$ relative density) compare to the $\mathrm{LC}$ coating $\left(0.723 \mathrm{~W} \cdot \mathrm{m}^{-1} \mathrm{~K}^{-1}\right.$ at $1573 \mathrm{~K}$ with $75.4 \%$ relative density), and also exhibited excellent phase stability between room temperature and 1773K. Dilatometric measurements(1573K , 5h) of the plasma-sprayed coatings showed that lower sintering rate for LC coatings with 5 mass $\%-10$ mass $\%$ YSZ doped, shrinkage rate decreased from $0.59 \%$ (LC coating) to $0.1 \sim 0.25 \%$ (5mass $\%$ - 10 mass $\%$ doped).

\section{Introduction}

Thermal barrier coatings (TBCs) have been widely used on the surfaces of high-pressure turbine blades and vanes in aero engines due to its heat insulation, oxidation and corrosion resistance ability for hot-section components [1]. Partially $\mathrm{Y}_{2} \mathrm{O}_{3}$ stabilized $\mathrm{ZrO}_{2}$ (YSZ) has been used as state-of-the-art thermal barrier coating (TBC) materials due to its high linear thermal expansion coefficient $\left(9 \times 10^{-6}\right.$ $\left.\mathrm{K}^{-1}-10.5 \times 10^{-6} \mathrm{~K}^{-1}\right)$ as well as low thermal conductivity $\left(2.0 \mathrm{Wm}^{-1} \mathrm{~K}^{-1}\right.$ at $\left.1273 \mathrm{~K}\right)$, but it cannot be long-term used above $1473 \mathrm{~K}$ because of accelerated sintering and phase transformation $[2,3]$. In the search of next generation TBC materials that can be used at higher temperatures, lanthanum cerate $\left(\mathrm{La}_{2} \mathrm{Ce}_{2} \mathrm{O}_{7}, \mathrm{LC}\right)$ has been found to have low thermal conductivity $\left(0.52 \mathrm{Wm}^{-1} \mathrm{~K}^{-1}\right.$ at $\left.1273 \mathrm{~K}\right)$ than most of other TBC candidates, excellent high temperature phase stability and high linear thermal expansion coefficient, as the potential material for the TBC application [4-6]. Sintering-resistance above $1473 \mathrm{~K}$ has very important applications in new TBCs, which decided the capacities of heat insulation and strain tolerance during the long-term high temperature service condition [7, 8]. Cao [9] has been reported that sintering temperature of LC coating from plasma sprayed is about $1518 \mathrm{~K}$, which is lower than the target service temperature $(\sim 1573 \mathrm{~K})$ of next generation TBCs. Among the interesting TBCs candidates, $\mathrm{La}_{2} \mathrm{Zr}_{2} \mathrm{O}_{7}(\mathrm{LZ})$ is a typical rare earth zirconate with pyrochlore structure, and it has a lower thermal conductivity $\left(1.56 \mathrm{Wm}^{-1} \mathrm{~K}^{-1}\right)$ than YSZ [10]. $\mathrm{La}_{2}\left(\mathrm{Zr}_{0.7} \mathrm{Ce}_{0.3}\right)_{2} \mathrm{O}_{7}$ (LZ7C3) with the mixture of pyrochlore and fluorite structures exhibited higher sintering-resistance and fracture toughness than LC, and sintering temperature of its coatings is about $1663 \mathrm{~K}[4,11]$.

In the present work, a way for improving the sintering-resistance, fracture toughness and retaining low thermal conductivity of LC with fluorite structure is presented. The LC modified materials with doping 7YSZ by the solid-phase synthesis, the phase stability and thermophysical properties of 
coatings prepared by plasma spraying were studied. LC coatings with 7YSZ doped has obviously higher sintering-resistance at $1573 \mathrm{~K}$ than tradition LC. The reason for choosing 7 YSZ for LC modified is not only its relatively high thermal expansion coefficient and widely used for TBCs, but also martensitic transformation toughening and nanostructure effect on fluorite structural LC with low fracture toughness.

\section{Experimental}

$\mathrm{La}_{2} \mathrm{Ce}_{2.5} \mathrm{O}_{8}$ and $\mathrm{YSZ}$ ( 7 mass $\% \mathrm{Y}_{2} \mathrm{O}_{3}-\mathrm{ZrO}_{2}$ ) synthesized by the method of chemical coprecipitation, and its doped compounds (1YZLC (99\%- $\left.\mathrm{La}_{2} \mathrm{Ce}_{2.5} \mathrm{O}_{8}+1 \%-\mathrm{YSZ}\right), 2.5 \mathrm{YZLC}, 5 \mathrm{YZLC}, 7.5 \mathrm{YZLC}$ and 10YZLC) with 1 mass $\%, 2.5$ mass $\%$, 5mass $\%$, 7.5mass $\%$ and 10mass $\%$ 7YSZ prepared by the solid-phase synthesis at $1673 \mathrm{~K}, 24 \mathrm{~h}$. An optimum composition of LC for this work is considering the volatilization of $\mathrm{CeO}_{2}$ during plasma spraying process, and it has been approved by $\mathrm{Ma}$ [12].Since the coating composition after the spraying is close to stoichiometric $\mathrm{La}_{2} \mathrm{Ce}_{2} \mathrm{O}_{7}$, the coating is named also as $\mathrm{La}_{2} \mathrm{Ce}_{2} \mathrm{O}_{7}$ (LC). Mixed powders with $\mathrm{La}_{2} \mathrm{Ce}_{2.5} \mathrm{O}_{8}$ and 7YSZ were ball-milled for $12 \mathrm{~h}$ in distilled water with zirconia balls. The mixture was heated at $1673 \mathrm{~K}, 12 \mathrm{~h}$ for solid phase synthesis. Sprayed powders for plasma spraying were prepared by agglomerated-sintering method, $\mathrm{La}_{2} \mathrm{Ce}_{2.5} \mathrm{O}_{8}$ and its doped compounds were ball-milled $2 \mathrm{~h}$ in distilled water with $50 \%$ solid content, and then used for spray drying. Sprayed powders were sintered at $1673 \mathrm{~K}, 20 \mathrm{~min}$ with heating rate of $5 \mathrm{~K} / \mathrm{min}$. Sprayed powders with particle size of $45 \mu \mathrm{m}$ to $98 \mu \mathrm{m}$, and loose density approximately $1.7 \mathrm{~g} / \mathrm{cm}^{3}$.

The ceramics coatings were prepared by the same process condition with atmospheric plasma spraying (APS) on stainless substrate. The spray parameters are as follows: current $=600 \mathrm{~A}$, voltage $=70$ $\mathrm{V}$, powder feeding rate $=20-30 \mathrm{~g} / \mathrm{min}$, spray distance $=80 \mathrm{~mm}$. After APS process, detached the ceramics coatings from the stainless substrate, and with dimension of $\Phi 12.7 \times 2.5 \mathrm{~mm}$ and $\Phi 8 \times 3 \mathrm{~mm}$. Carborundum abrasive paper of 1000\# was used to polish the ceramic coatings, with final dimension of $\Phi 12.7 \times 2 \mathrm{~mm}$ for thermal diffusivity test and $\Phi 6 \times 2 \mathrm{~mm}$ for thermal dilatometer test.

Crystal structure was characterized by X-ray diffraction (XRD, Bruker D8, CuKa radiation). Thermal diffusivity was recorded by using a laser flash method (Netzsch LFA427) with heating rate of $5 \mathrm{~K} / \mathrm{min}$. The dilatometric measurements of the plasma-sprayed coatings were finished on a dilatometer (Netzsch DIL 402C) from room temperature to $1573 \mathrm{~K}$ with heating rate of $10 \mathrm{~K} / \mathrm{min}$, and $5 \mathrm{~h}$ heat preservation at $1573 \mathrm{~K}$ for obtaining the dimensional changes through coating thickness. The differential scanning calorimetry (DSC) analysis for phase stability from room temperature to $1773 \mathrm{~K}$ was conducted by using simultaneous thermal analysis apparatus (NETZSCH STA 449F3). The densities $(\rho)$ of coatings were measured according to the Archimedes principle. The specific heat capacity $\left(\mathrm{C}_{\mathrm{p}}\right)$ was determined as a function of temperature from the chemical compositions of coatings and the heat capacity data of the constituent oxides $\left(\mathrm{La}_{2} \mathrm{O}_{3}, \mathrm{CeO}_{2}, \mathrm{Y}_{2} \mathrm{O}_{3}\right.$ and $\left.\mathrm{ZrO}_{2}\right)$ obtained from the literature [13] in conjunction with the Neumann-Kopp rule [14].

\section{Results and discussion}

\section{Phase structure and stability of doped compounds and coatings}

$\mathrm{LC}$ is a solid solution of $\mathrm{La}_{2} \mathrm{O}_{3}$ in $\mathrm{CeO}_{2}$ with a fluorite $(\mathrm{F})$ type structure, when 7YSZ doped, $\mathrm{Y}^{3+}$ replace the crystal lattice of $\mathrm{La}^{3+}$ and $\mathrm{Zr}^{4+}$ replace the crystal lattice of $\mathrm{Ce}^{4+}$. For different compositions of 7YSZ doped LC, maybe form a LC and LZ (pyrochlore, P) mixed compound. The XRD patterns of $\mathrm{La}_{2} \mathrm{Ce}_{2.5} \mathrm{O}_{8}$ and its doped powders as shown in Fig.1. Main peak of pyrochlore is clearly appearing in Fig.1 (e), (f) and (g), and increase with the content of 7YSZ. Fluorite peaks have no obviously change below 5 mass $\% 7$ YSZ doped.

XRD patterns of as-sprayed coatings are shown in Fig.2. LC coating and coatings doped with 7YSZ have a single fluorite structure, peaks of pyrochlore composites in powders of 5YZLC, 7.5YZLC and 10YZLC disappeared in the plasma spraying process. Vapor pressures of $\mathrm{CeO}_{2}\left(2 \times 10^{-2} \mathrm{~atm}, 2500{ }^{\circ} \mathrm{C}\right)$ is higher than that of $\mathrm{La}_{2} \mathrm{O}_{3}\left(8 \times 10^{-5}\right.$ atm, $\left.2500{ }^{\circ} \mathrm{C}\right)$, which indicate $\mathrm{CeO}_{2}$ content lose is high in plasma 
spraying. In the quickly melt and cooling process, $\mathrm{Zr}^{4+}$ in pyrochlore composite fill the vacancy which left by $\mathrm{Ce}^{4+}$ volatilized in LC, maybe the main reason for peaks of pyrochlore disappeared.

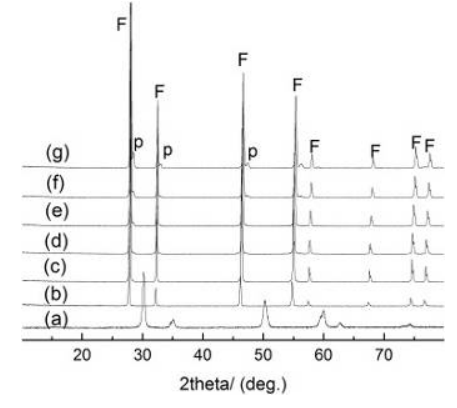

Fig1

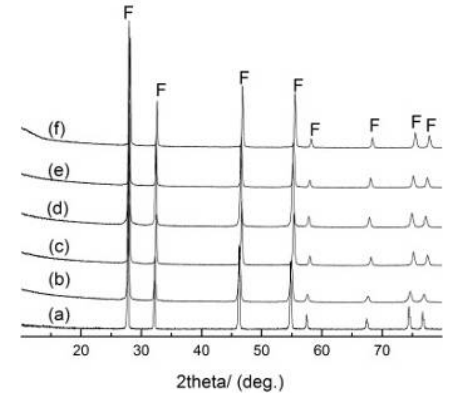

Fig.2

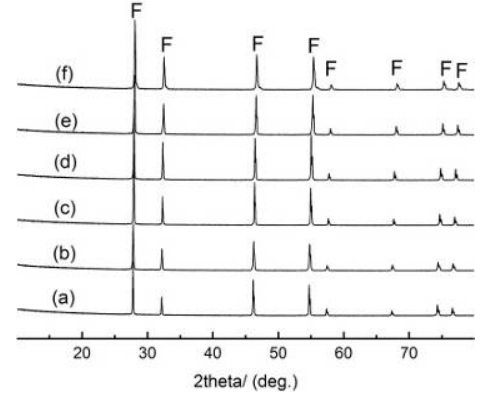

Fig. 3

Fig.1 XRD patterns of powders: (a) 7YSZ, (b) La2Ce2.5O8, (c) 1YZLC, (d) 2.5YZLC, (e) 5YZLC, (f) 7.5YZLC and (g) 10YZLC.

Fig.2 XRD patterns of as-sprayed coatings: (a) LC, (b) 1YZLC, (c) 2.5YZLC, (d) 5YZLC, (e) 7.5YZLC and (f) 10YZLC.

Fig.3 XRD patterns of as-sprayed coatings after 50h annealed at 1673K: (a) LC, (b) 1YZLC, (c) 2.5YZLC, (d) 5YZLC, (e) 7.5YZLC and (f) 10YZLC.

Fig. 3 is XRD patterns of LC coating and coatings with 7YSZ doped after annealing at 1673K, 100h, no obvious change was observed during the annealing process, which means that LC coating and coatings with 7YSZ doped have high phase stability at 1673K, implying that LC doped with 7YSZ might be suitable for TBC applications at least up to $1573 \mathrm{~K}$. In the coating with 10mass $\%$ YSZ doped (10YZLC), a feebleness peak of pyrochlore appears on the left of the main peak of fluorite. Fig.4 is DSC curve of coatings with 7YSZ doping LC between room temperature and 1773K. This figure also reveals that LC coatings with 7YSZ doped exhibit excellent phase stability in the tested temperature range.
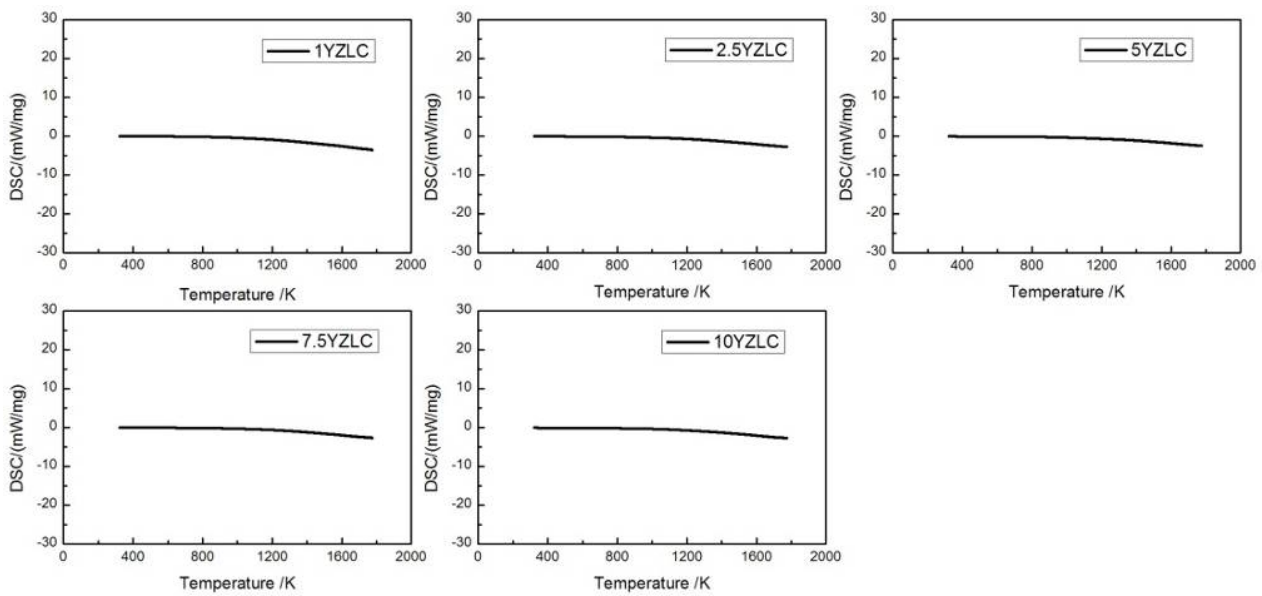

Fig.4 DSC curves of coatings doped with 7YSZ.

\section{2 sintering-resistances of $L C$ and its doped coatings}

In order to study the sintering-resistance of the coatings doped with 7YSZ, the dilatometric properties of these coatings are measured as shown in Fig.5. Calculated the shrinkage rate between the end and start of the heat preservation period, the sintering-resistance is not clearly change of the coating with 1 mass $\%$ and 2.5 mass $\%$ 7YSZ doped. When content of 7 YSZ above 5 mass $\%$, the sintering-resistance obviously improves compare with LC coating. Under the measured condition close to the target service temperature, ability of sintering-resistance of LC coating improve 5 times through nano 7YSZ doped. Shrinkage rate decreased from $0.59 \%$ (LC coating) to $0.1 \sim 0.25 \%$ (5mass\%-10mass\% doped). 


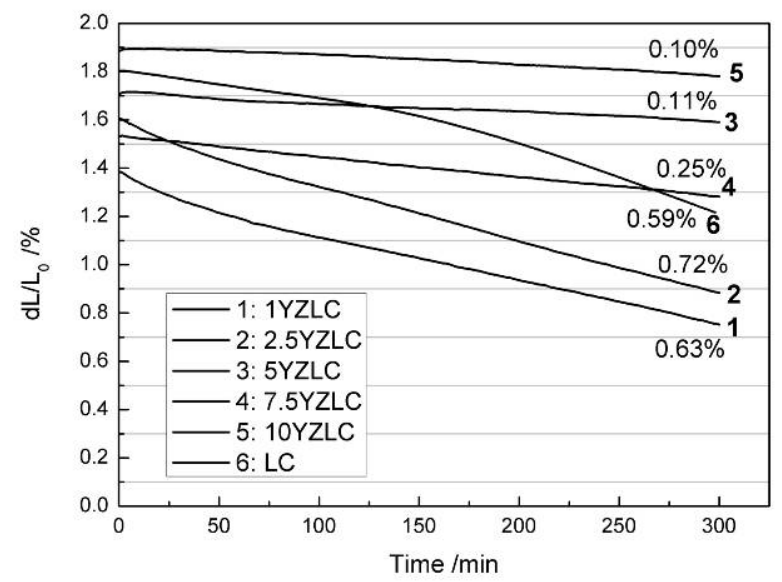

Fig.5 Shrinkage behavior of the LC coating and its coatings doped with 7YSZ.

3 Thermal conductivity of plasma sprayed LC and its doped coatings

Relative density of coatings is shown in Fig.6, LC coating with the lowest relative density by the same spraying process, and narrow distribution of the relative density of the coatings at $75 \%$ to $85 \%$. The thermal diffusivities of LC and its coatings doped with 7YSZ decrease with the increasing of temperature in the range between ambient and $1400 \mathrm{~K}$, which is plotted in Fig. 7(a). A slightly increase trend of thermal diffusivity of coating above $1400 \mathrm{~K}$ was observed. Thermal diffusivities of coatings with doped content above 2.5 mass $\%$ are lower than LC coating above $600 \mathrm{~K}$, nano pores contributed by 7YSZ and low thermal diffusivity of nano YSZ may be the main reason for this phenomenon.

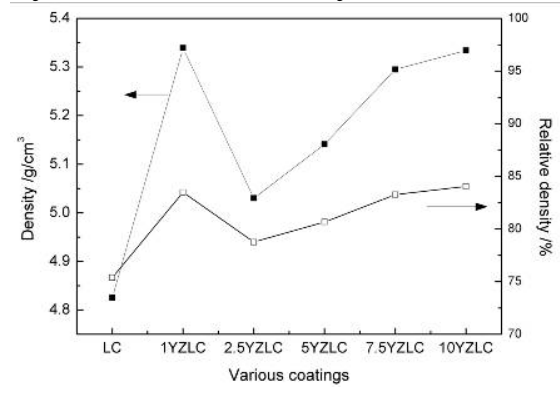

Fig.6 Density and relative density of various coatings.
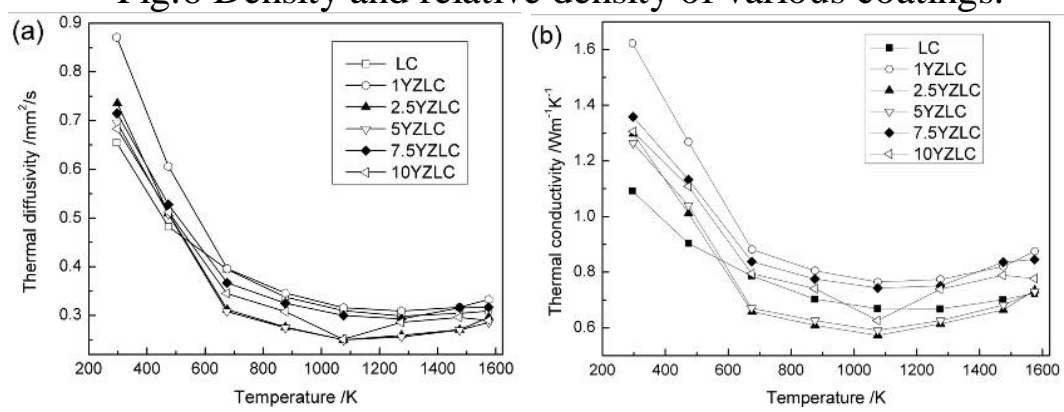

Fig.7 Thermal diffusivities (a) and thermal conductivities (b) of coatings for various temperatures.

Thermal conductivities $\mathrm{K}$ were calculated using the Eq. (1) with the heat capacity $\mathrm{Cp}$, density $\rho$ and thermal diffusivity $\lambda$.

$$
\mathrm{k}=\mathrm{C}_{\mathrm{p}} \times \lambda \times \rho
$$

The values of thermal conductivity are observed in Fig. 7(b). The LC coatings doped with 7YSZ retain lower thermal conductivities $\left(0.7 \sim 0.8 \mathrm{~W} \cdot \mathrm{m}^{-1} \mathrm{~K}^{-1}\right.$ at $1573 \mathrm{~K}$ with about $80 \%$ relative density) compare to the LC coating $\left(0.723 \mathrm{~W} \cdot \mathrm{m}^{-1} \mathrm{~K}^{-1}\right.$ at $1573 \mathrm{~K}$ with $75.4 \%$ relative density), and thermal conductivities change with relative density of coatings, which increase with relative density as shown in Fig.6. Considering the affection of porosity, the method of 7YSZ doped for LC coating would not decrease the thermal conductivity of coating at a certain range of doped content.

The thermal conductivity of 7YSZ is higher than LC, changing of mean free path of phonon maybe the reason for thermal conductivity retaining of LC coatings doped with 7YSZ. X-LC+(1-X)-7YSZ 
mixed, high temperature sintered and sprayed to form coatings, a mixture with $\mathrm{La}_{2} \mathrm{Ce}_{2} \mathrm{O}_{7}$, $\left(\mathrm{La}_{1-\mathrm{a}} \mathrm{Y}_{\mathrm{a}}\right)_{2}\left(\mathrm{Zr}_{\mathrm{b}} \mathrm{Ce}_{1-\mathrm{b}}\right)_{2} \mathrm{O}_{7}$ and single rare earth oxide or YSZ maybe present in the coating. Combine with the affect by nano pores, length of mean free path of phonon decrease in the mixture compare with pure material, which is the reason for LC coatings doped with 7YSZ exhibit low thermal conductivity.

\section{Conclusions}

7YSZ doped LC materials were synthesized by the solid-phase synthesis method, all of coatings exhibit a single fluorite structure and excellent high temperature phase stability. Thermal conductivity of LC coatings doped with 7YSZ was closed to the origin LC coating, and sintering-resistance of coatings with doped content above 5mass\% was obviously improve compare with origin LC coating.

\section{References}

[1] N.P. Padture, M. Gell, E.H. Jordan, Science 296 (2002) 280-284

[2] D. Stoever, G. Pracht, H. Lehmann, M. Dietrich, J.E. Doering, R. Vassen, New material concepts for the next generation of plasma-sprayed thermal barrier coatings, Journal of Thermal Spray Technology 13 (2004) 76-83

[3] X.Q. Cao, R. Vassen, and D. Stöver, "Ceramic Materials for Thermal Barrier Coatings," J. Europ. Ceram. Soc., 24 [1] 1-10 (2004)

[4] W. Ma, S.K. Gong, H.B. Xu, X.Q. Cao, Surf. Coat. Technol. 200 (2006) 5113-5118.

[5] S. Sodeoka, M. Suzuki, T. Inoue, K. Ueno, S. Oki, in: Proceedings of the 9th National Thermal Spray Conference on "Practical Solutions for Engineering Problems", 1996, pp. 295-302

[6] Wen Ma, Shengkai Gong, Hefei Li, Huibin Xu, Novel thermal barrier coatings based on La2Ce2O7/8YSZ double-ceramic-layer systems deposited by electron beam physical vapor deposition. Surface \& Coatings Technology 202 (2008) 2704-2708

[7] R.Vassen, X.Cao,F. Tietz,D. Basu,D. Stoever, J.Am. Ceram.Soc.83(2000) 2023-2028.

[8] Z.-G. Liu, J.-H. Ouyang, Y. Zhou, J. Li, X.L. Xia, Int. J. Ceram. Technol. 6 (4) (2009) 485-491.

[9] X.Q. Cao, R. Vassen, F. Tietz, D. Stöver, J. Eur. Ceram. Soc. 26 (2006) 247-252.

[10] B. Saruhan, P. Francois, K. Fritscher, U. Schulz, Surf. Coat. Technol. 182 (2004)175-183.

[11] X.Q. Cao, R. Vassen, W. Fischer, F. Tietz, W. Jungen, D. Sto“ ver, Adv. Mater. 15 (17) (2003) $1438-1442$

[12] W. Ma, Y. Ma, S. Gong, H. Xu, X. Cao, Key Eng. Mater. 336-338 (2007) 1759.

[13] O. Kubaschewsji, C.B. Alcock, P.J. Spencer, Materials Thermochemistry, 6th ed., Pergamon Press, Oxford, 1993, pp. 257-323.

[14] R.A. Swalin, Thermodynamics of Solids, 2nd ed., John Wiley \& Sons, New York, 1972, pp. 53-87.

[15] J. Wu, X.Z. Wei, N.P. Padture, P.G. Klemens, M. Gell, E. Garcia, J. Am. Ceram. Soc. 85 (2002) 3031. 